\title{
APPLICATION OF FLYWHEEL ENERGY STORAGE AND PERMANENT MAGNET SUSPENSION TECHNOLOGY
}

Li Weili ${ }^{1}$, Xue Yi $^{2}$, Shen jiafeng ${ }^{3}$, Yang shaohua ${ }^{4}$ ${ }^{1-}$ School of Electrical Engineering, Beijing Jiaotong University

2- School of Electrical and Control Engineering, ${ }^{3-}$ Harbin University of Science and Technology

4-Jiang Su Weiteli Motor Limited By Share Ltd, Taizhou

\section{Introduction}

Flywheel energy storage is an important way to make effective use of new energy sources and improve the quality of power supply. It is also an important way to improve power quality. As one of the earliest laboratories in China to study flywheel energy storage, Tsinghua University and Sinopec Group jointly developed China's first flywheel energy storage system prototype of $400 \mathrm{~kW}$ in 2012. The system breaks through the key technical problems such as permanent magnet bearings, high-speed permanent magnet motors, high-power charge and discharge controllers. The quality of flywheel is $2 \mathrm{t}$, the total storage energy is $16.3 \mathrm{MJ}$, and the efficiency of energy conversion can reach to $86 \%^{[1]}$. Li Weili, the Professor of Beijing Jiaotong University, who developed a new structure of metal flywheel can store $200 \mathrm{~kW}$ of energy and speed up to $15,000 \mathrm{r} / \mathrm{min}$.

II. Analysis of mechanical structure of energy storage flywheel

From the formulas of flywheel's energy storage we can know that when the speed and volume is constant, the flywheel's 
energy storage and density are impacted of its rotational inertia. The flywheel's rotational inertia is:

$$
J=2 \pi \rho \int_{r_{0}}^{r_{1}} h_{2} r^{3} d r+2 \pi \rho \int_{r_{1}}^{r_{2}}\left[h_{2}-2\left(r-r_{1}\right) \tan \theta\right] r^{3} d r
$$

The density of energy storage:

$$
E_{S D}=\frac{e}{m}=\frac{1}{2} R^{2} \omega^{2}
$$

\section{$P:$ The density of flywheel}

${ }^{\omega}$ : The rotation angular velocity of flywheel.

We can open the weight hole in the flywheel to improve the density of energy storage. Fig. 1 is Structure of flywheel.

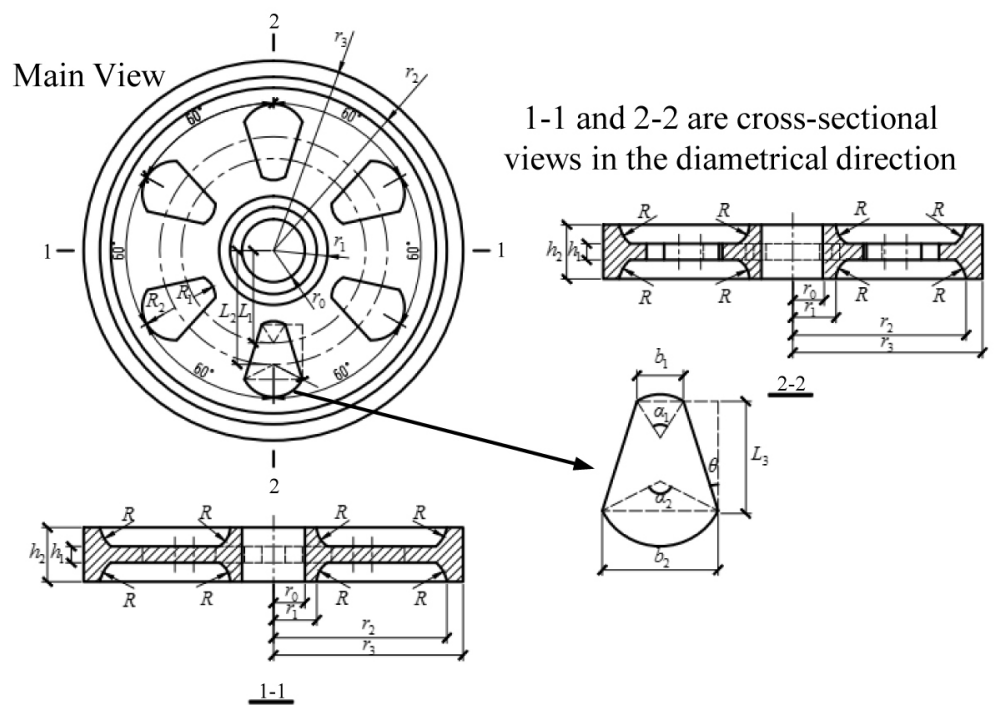

Fig. 1. Structure diagram of Metal flywheel 


\section{PM Suspension Technology}

PM suspension bearings are supplied by permanent magnets. Compared with the electromagnetic bearing, the permanent magnet bearing has the characteristics of simple design and easy assembly, which can simplify the system structure, reduce the difficulty of design and assembly and provide convenient conditions for the development of flywheel technology.

Overall, using permanent magnetic suspension technology in the flywheel energy storage system can improve the performance of the system which is important to improve the density of flywheel system.

\section{Information about authors:}

Li Weili, Ph. D. School of Electrical Engineering,

Beijing Jiaotong University

E-mail: li.weili@yeah.net 